Pensamiento Crítico Vol. 18 № 1, pp. 123-130

\title{
Desarrollo rural: parques agroindustriales
}

\author{
MG. Enrique E. Palacios Lozada
}

\section{RESUMEN}

Los diferentes modelos de desarrollo rural aplicados, han tenido como base conceptual la modernidad y el incremento de la producción y productividad agropecuaria, factores necesarios pero no suficientes para explicar el funcionamiento de la sociedad rural y su desarrollo.

El modelo propuesto esta basado en la implementación de parques agroindustriales los cuales permiten desarrollo tecnológico, mayor valor agregado, generación de empleo y desarrollo de gestión. Su importancia y aplicabilidad permiten resolver temas de estructura y coyuntura del mundo rural.

Palabras claves: Desarrollo, Desarrollo rural, parques agroindustriales.

\section{SUMMARY}

Several rural development models have been implemented with a conceptual basis of modernity; increased production and agricultural productivity, factors required but not sufficient to sustain the operation of rural society and its development. 


\section{Pensamiento Crítico Vol. I8. Nº}

The proposed model is based on the implementation of agroindustry parks which allow: technological development, higher added value, employment generation and management development. Its importance and applicability provide a solution to structural issues and conjuncture of the rural world.

Keywords: Development, Rural development, agro-industrial parks.

\section{INTRODUCCIÓN}

El tema del desarrollo es complejo y conceptualmente no existe un consenso sobre su definición. Sin embargo, en términos generales lo que se busca es incrementar el bienestar y los derechos humanos de las poblaciones de un país. A lo que se agrega el término de desarrollo sustentable.

Toda noción de desarrollo como lo señala Orlando Plaza, involucra una teoría del cambio social. La interpretación del contenido, los agentes, la discrecionalidad, los instrumentos y los medios para lograr el cambio están directamente relacionados con posiciones ideológicas, es decir, como lograr el cambio hacia donde dirigirlos y a quiénes beneficiar.

El considerar a los gobiernos sin ninguna posición ideológica es una falacia, lo cierto y real es que los gobiernos no han priorizado el desarrollo rural.

Los economistas y estudiosos del desarrollo señalan con toda claridad que país que no resuelva su problema agrario no puede alcanzar el desarrollo. La producción agrícola y la soberanía alimentaria son necesarias para el desarrollo de los pueblos. Además es la base alrededor de lo cual se organizan las sociedades rurales.

El desarrollo agrícola no sólo es un problema de innovación tecnológica, de inversión, de mercado, de calificación del recurso humano, etc. Sino esencialmente es un tema de decisión política del estado, quien elabora y ejecuta la estrategia de desarrollo del país. 


\section{Enrique E. Palacios Lozada}

El desarrollo agrícola es parte del desarrollo rural, por eso es inadecuado e intrascendente pretender realizar un Plan de Desarrollo Rural aislado del plan de desarrollo estratégico del país.

Al medio rural se le caracteriza por su posición declinante en el contexto nacional, donde la condición de vida del habitante rural es de menor calidad y presenta un alto porcentaje de pobreza y de exclusión social y política.

\section{DESARROLLO RURAL}

El tema del desarrollo es complejo tanto en la realidad como conceptualmente, por las múltiples dimensiones que comprende: económicas, sociales, políticas, tecnológicas, espaciales etc.

La definición de desarrollo rural no escapa a esta complejidad real y conceptual. Sin embargo implica un conocimiento de la forma como esta organizada y se reproduce la sociedad rural, un análisis de las articulaciones económicas, sociales y políticas en el interior de esta sociedad rural y sus vinculaciones con la sociedad nacional y global. El rol que cumple el Estado y las instituciones civiles.

Razón más que suficiente para señalar que el desarrollo rural tiene que estar inscrito en una propuesta de desarrollo del país.

Hace décadas que se viene abordando la temática del desarrollo rural, bajo diferentes enfoques. Hoy se analiza bajo el concepto de nueva ruralidad y desarrollo territorial.

Sin embargo es necesario señalar que los problemas estructurales de la sociedad rural siguen vigentes y no han podido ser solucionados por ninguno de los enfoques de desarrollo rural.

Por décadas los modelos de desarrollo rural en el Perú como en otros países con población rural significativa, han estado basados en una visión que miraba al sector rural como agrícola, desligándolo de su entorno urbano y de las actividades multisectoriales 


\section{Pensamiento Crítico Vol. I8. Nº}

existentes por lo tanto se le aplicaban políticas de desarrollo agrario. Al campo se le vio como abastecedora de la ciudad y nunca se entendió como podrían establecerse relaciones de intercambio más equitativas entre el campo y la ciudad. Lo que explica que los diferentes modelos de desarrollo rural han tenido como base el desarrollo agropecuario por lo que ha tenido una conceptualización y aplicación sectorial. Han considerado como base conceptual la modernidad, y el incremento de la producción, productividad y el acercamiento a los mercados; factores necesarios pero no suficientes para explicar el funcionamiento de la sociedad rural y su desarrollo.

El mundo rural es más complejo y diverso que lo agropecuario, pero este sigue siendo importante, donde coexisten una multiplicidad de actividades (artesanía, turismo, industria, etc.) articuladas a lo rural.

El sector agrario ha perdido ponderación dentro de la sociedad rural, señalándose que el $51 \%$ de los ingresos provienen de actividades no agrícolas. Sin embargo la agricultura sigue siendo la actividad económica más significativa en la sociedad rural.

El nuevo paradigma de desarrollo rural está centrado en los conceptos de nueva ruralidad y competitividad territorial.

La nueva ruralidad que consiste en reconocer que lo rural no sólo es lo agrario, sino que coexisten otras actividades como lo artesanal, turístico, industrial, etc. Que permiten generar empleo e ingreso a la población rural.

Lo territorial que reconoce la heterogeneidad del ámbito rural, donde se desarrollan aspectos multifuncionales y de pluriactividades lo que permite proponer estrategias diferenciadas para los distintos territorios.

Enfoque orientado al crecimiento endógeno local, regional y descentralizado; que requiere el acceso y desarrollo de los mercados, así como la accesibilidad de los bienes y servicios públicos. 


\section{Enrique E. Palacios Lozada}

Enfoque que reconoce que existe una interdependencia entre lo urbano y lo rural que no sólo se refiere a la producción y consumo de alimentos, sino de redes sociales, las comunicaciones, el mercado laboral. Entre otros aspectos.

En las áreas rurales se encuentra la tercera parte de la población nacional y de la población económica activa del País. Población que presentan altos niveles de pobreza y exclusión aspectos que de por sí, determinan la necesidad de todo gobierno de priorizar el desarrollo rural como parte integrante de una estrategia de desarrollo nacional.

Estrategia que reduzca la pobreza y exclusión rural; donde el crecimiento económico nacional y el entorno macroeconómico favorable son necesarios pero no suficientes para lograr estos objetivos, tal como lo demuestran los hechos reales hoy.

Y donde el proceso de globalización implica una mayor integración de las economías, y que constituye una fuente de oportunidades y desafíos. Pero que implica un debilitamiento del binomio Estado-nación y de la soberanía de las políticas nacionales frente al mercado mundial. Donde existe predominancia de ciertos Estados y de empresas transnacionales que determinan las relaciones existentes que se establecen en los mercados mundiales y que influyen en las políticas de desarrollo rural.

Los creadores de enfoques y políticas de desarrollo rural poseen sin duda un conocimiento académico-científico y técnico que el sujeto rural no lo tiene, pero no tiene un conocimiento total de su vida y de su lógica de actuar. Por lo que es necesario establecer una relación igualitaria y participativa entre el sujeto y el objeto de lo que se investiga o quien va a afectar las políticas que se propone.

Existe una insuficiente relación dialéctica entre los enfoques teóricos y la realidad. No es posible considerar a las sociedades rurales y sus espacios como estáticos, son realidades cambiantes, donde el Estado ha cumplido un rol con sus actividades y políticas, las cuales no han favorecido a los más pobres y excluidos y cuyos porcentajes en la sociedad rural tiene niveles significativos. 


\section{Pensamiento Crítico Vol. 18. Nº}

En resumen el desarrollo rural es un tema de decisión política que tiene que ser abordado dentro de un plan estratégico de desarrollo nacional; donde las leyes, planes y programas por si solos no cambian la realidad.

\section{PARQUES AGROINDUSTRIALES}

Es una zona reservada en los espacios rurales para la realización de actividades industriales productivas correspondientes al sector industrial que usan como in sumo principal productos agropecuarios.

Cuya área esta dotada de infraestructura, equipamiento y servicios comunes y servicios públicos necesarios, para la instalación y funcionamiento de los parques agroindustriales.

Los parques agroindustriales han sido utilizados como ejes de desarrollo rural en otros países como México, Colombia etc.

Los Parques agroindustriales planteados no requieren montos elevados para su implementación y tienen como meta:

1. Desarrollo tecnológico del agro, generando un valor agregado a los productos agropecuarios.

2. Generación de empleo.

3. Desarrollo de gestión del productor agropecuario.

4. Prolonga el tiempo de perecibilidad de los productos agropecuarios.

5. Se mejora la comercialización y colocación en los mercados.

6. Fomenta la inversión.

7. Mejora el nivel de vida del poblador rural.

8. Mayor integración con la industria. 


\section{Enrique E. Palacios Lozada}

Un modelo de desarrollo rural basado en la instalación y funcionamiento de parques agroindustriales, aun cuando se presente en forma simple, es una construcción compleja que encierra: diagnostico, objetivos a alcanzar y procedimientos.

Diagnostico: la sociedad rural sigue mostrando los síntomas de atraso productivo y de pobreza.

Objetivos: superar el atraso productivo y la pobreza. Mejorando el empoderamiento y la participación.

Procedimiento: Parques agroindustriales.

El utilizar como eje los parques agroindustriales implica un sistema que integra el proceso productivo, industrial y de comercialización; donde la competitividad total es resultado de las competitividades de cada uno de estos procesos.

No solo es un sistema de enseñar mejores técnicas productivas, sino de convertir al agricultor en un buen empresario capaz de hacer al sector rural en rentable y competitivo.

El impulso para la instalación y funcionamiento de parques agroindustriales requiere de implementar políticas públicas que estimulen el proceso de inversión, tanto de empresarios como agricultores.

\section{CONCLUSIONES}

1. El mundo rural es mas complejo y diverso que lo agropecuario, pero lo agrario sigue siendo importante, donde coexisten una multiplicidad de actividades sectoriales (artesanía, industria , minería, turismo etc) y de servicios articulados a lo rural.

2. Los diferentes modelos de desarrollo rural aplicados, han tenido como base conceptual la modernidad y el incremento de la producción y productividad, factores necesarios pero no suficientes para explicar el funcionamiento de la sociedad rural y su desarrollo 


\section{Pensamiento Crítico Vol. 18. N I}

3. En el Perú se han aplicado diferentes programas de desarrollo rural, sin provocar cambios sustantivos en la sociedad rural.

4. El implementación de los parques agroindustriales requiere de la intervención del estado de las autoridades regionales y locales, así como de la sociedad civil (empresarios y agricultores).

5. El funcionamiento de los parques agroindustriales garantizan un mayor valor agregado a los productos agropecuarios. Así como mayor empleo e Inversión.

6. Una estrategia de desarrollo rural solo tiene futuro en tanto sea asumida como parte de la estrategia de desarrollo del país, y a la vez referida a la noción de que sin desarrollo rural no hay desarrollo del país.

\section{BIBLIOGRAFÍA}

Desarrollo Rural: Mendieta, Claudia, Agreda, Víctor Cies.

Desarrollo Territorial Rural. Schejtman, Alexander. Santiago de Chile.

Desarrollo Rural. Plaza, Orlando. PUC.

Desarrollo Rural en América Latina y el Caribe CEPAL.

Desarrollo Rural. Sancho, José. PARANINFO.

Enfoques sobre desarrollo Rural en América Latina, Europa. Kay, Cristóbal.

Estrategias y políticas de desarrollo rural. Trivelli, Carolina. Economía, Sociedad CIES.

La Nueva Ruralidad en Europa y su interés para América Latina. Pérez,Antonio; Caballero, José María FAO.

Nueva Ruralidad y Competitividad Territorial. Eguren, Fernando; Pérez,Edelmira IDEAS.

Reforma Agraria y Desarrollo Rural en la región Andina. Eguren, Fernando. CEPES. 